\title{
Effect of Initial Cylinder Liner Honing Surface Roughness on Aircraft Piston Engine Performances
}

\author{
Paweł Woś • Jacek Michalski
}

Received: 15 October 2009/Accepted: 3 December 2010/Published online: 6 January 2011

(C) The Author(s) 2010. This article is published with open access at Springerlink.com

\begin{abstract}
Reciprocating piston engines are the major propulsion devices for light aircrafts, helicopters, and essentially all automotive vehicles. They are expected to fulfil both present-day and future demands for engine performance, durability, fuel economy, and exhaust emissions legislation. One of the key factors related to these demands is the need to the limit thermomechanical internal losses, wear, and lubricating oil consumption, which are in turn conditioned by the tribological behavior of the piston-cylinder assembly. Consequently, this latter system requires a multi-directional approach in terms of manufacturing. Apart from various modifying techniques (e.g. laser texturing), a conventional plateau-honing operation is still the standard technology for shaping cylinder liner surface microstructure. This paper describes the distinctions between variations in the performance of the engines in relation to cylinder liner roughness parameters due to different honing settings. Five air-cooled reciprocating aircraft engines (FRANKLIN 4A-235-B31) served as the objects of research. The engines passed durability tests on the dynamometer bed, including operation under artificially intensified wear conditions. The results show a significant impact of the brand-new honed cylinder liner surface microstructure on the engine output parameters. Detailed study proves that some of the cylinder liner roughness parameters, specifically, the slope of the root mean square
\end{abstract}

P. Woś $(\bowtie) \cdot$ J. Michalski

Department of Mechanical Engineering and Aeronautics,

Rzeszów University of Technology, 8 Powstańców Warszawy

Av., 35-959 Rzeszów, Poland

e-mail: pwos@prz.edu.pl

J. Michalski

e-mail: jmichals@prz.edu.pl line (RMS) for valley roughness $R v q$ and the linear triangle area for valleys $A 2$, are strongly correlated with the engine operational properties. Higher values of $R v q$ and $A 2$ are associated with an improvement in engine performance but result in a deterioration in the exhaust harmful emission.

Keywords Gasoline internal combustion engine $\cdot$ Engine performance $\cdot$ Plateau honing - Piston-cylinder assembly . Cylinder liner - Surface roughness - Abrasive wear .

Tribological behavior
Abbreviations
A2 Roughness profile parameter-linear triangle area for valleys $(\mu \mathrm{m})$
$\mathrm{CO}$ Concentration of carbon monoxide in exhaust (\%)
$\mathrm{HC}$ Concentration of hydrocarbons in exhaust (ppm)
ge Brake-specific fuel consumption (BSFC; $\mathrm{g} / \mathrm{kW} \mathrm{h}$ )
$\mathrm{Ne} \quad$ Engine output power $(\mathrm{kW})$
Mo Engine output torque ( $\mathrm{N} \mathrm{m}$ )

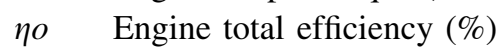
$\mathrm{P}-\mathrm{C}$ Piston-cylinder
$R q \quad$ Roughness profile parameter-root mean square of heights $(\mu \mathrm{m})$
$R v q$ Roughness profile parameter-slope of a linear regression of valley region $(\mu \mathrm{m})$

\section{Introduction}

The primary goals driving the development of combustion engines are to achieve low air pollution, high engine outputs, low thermal and friction losses, and low fuel and oil consumption. In addition to the engine running conditions 
and material characteristics of the mating elements, the microstructure of the cylinder liner surface is one of the main factors that impacts on engine internal friction losses and oil consumption. The proper manufacturing technology for the cylinder liner surface can ensure both the high performance and the durability of the engine. However, it is a difficult task to reconcile all these demands; thus, the engineering of combustion engines requires many tests, including simulations and tests under practical conditions with the end-product.

\section{Cylinder Liner Surface Shaping Technologies}

Plateau honing is the classical procedure currently utilized for finishing the cylinder liner surface. It provides a proper final surface morphology and depends on machining conditions, tool settings, among others. Thus, it is possible to vary roughness parameters so as to meet requested tribological behavior, which can be responsible for as much as $97 \%$ of lubrication oil consumption [1] and $45 \%$ of total mechanical losses [2]. Originally, a very smooth cylinder surface structure was recommended. However, this condition showed high wear resistance during the running-in period, although rough surfaces ensure great seizure resistance. Wiemann [3] found that the seizure resistance of cylinder liners is proportional to the surface roughness height. Subsequent researchers focusing on determining an optimum geometrical cylinder structure recommended a process of coarse honing followed by fine honing, a procedure which would superimpose one Gaussian distribution upon another. This approach is called plateau honing. Santochi and Vignale [4] found that plateau honing significantly shortened the costly running-in period because the surface achieved resembles a running-in surface. The plateau-honed cylinder surface ensures simultaneously the sliding properties of a smooth surface and a great ability to maintain oil on a porous surface. However, Jeng [5] reported that although plateaued surfaces are characterized by a shorter running-in period, they have a smaller seizure resistance in comparison to Gaussian surfaces of the same height standard deviation.

The importance of the honing process in finishing cylinder liners in order to promote satisfactory engine parameters and avoid scuffing is now well recognized, but not entirely understood [2]. For example, it is commonly known that increasing the oil retention capacity by deepening the valleys in the cylinder liner plateau profile results in a decrease of mechanical losses [4, 6-9]. The underlying mechanism of this reduction in mechanical losses at smaller roughness heights can be explained on a modified Stribeck curve [10] as being due to blow-by and cavitation phenomena [11]. On the other hand, such a microstructure of the plateau profile results in an increased lube oil consumption and exhaust emission of soot and particles (particulate matter), carbon oxides [carbon monoxide (CO), carbon dioxide $\left.\left(\mathrm{CO}_{2}\right)\right]$, and hydrocarbons $(\mathrm{HC})[6,12]$. The oil film thickness, pressure, and oil blow-by volume depend directly on the width and depth of honing scratches, and the distance between them [13]. Some models of friction and oil flow through the liner surface roughness are discussed by Jocsak et al. [14], including the gasoline and diesel engine performance parameters as a function of cylinder liner roughness heights, the distribution of their coordinates, honing crosshatch angle, and lubrication oil properties.

Owing to numerous findings in tribology research and a tendency towards manufacturing high power-to-mass ratio, downsized engines frequently endowed with new stateof-the-art technologies, such as variable valve actuation (VVA) or variable compression ratio (VCR) [15], a number of new approaches in plateau honing technology have emerged. One of these, characterized by a smooth surface and reduced depth of the base honing valleys, is slide honing [16]. The main objectives in developing this technology were to reduce wear, friction losses, and lube oil consumption while maintaining a productivity comparable with that of conventional plateau honing and achieving a high degree of reliability of the process itself and in mass production conditions, a long tool life, minimum deformation in the honed surfaces, i.e., minimal dislocations in the boundary layer, and the creation of a uniform and consistent surface over the whole cylinder bore. The scuffing resistance may be achieved by altering the geometry of basic honing valleys [17]. The finest material ratio parameters of the cylinder liner surface in terms of oil consumption and the emission of harmful exhaust compounds have been estimated for both cast iron liners [18] and liners made of aluminum alloys [19].

Further modification of slide honing procedure consists of increasing the honing angle by reducing the rotational speed of the honing tool. This slide/helical honing at a honing angle of $140^{\circ}$ is the next step for reducing emissions and extending oil change intervals [20]. Various endurance tests performed on six-cylinder production engines with liners made of standard gray cast iron have proved the advantages of helical honing: (1) the wear in the reversal zone was reduced by approximately $40 \%$ compared to the previous production honing process; (2) longterm oil consumption was reduced by $50 \%$ and remained very stable over the entire running-in time, with values between 0.04 and $0.05 \%$ of the fuel consumption [21]. Although the helical honing process is more expensive than slide honing, a comparatively new study carried out on a reciprocating tester found that, in general, such smoothed bore surfaces produce lower ring and bore wear [22]. 
Additional surface treatments may still improve the tribological behavior of sliding elements. The introduction of specific textures on a sliding surface, involving flat and smooth lands interrupted by local depressions, is the most common approach [23]. Various manufacturing techniques are utilized to produce regular micropits on sliding surfaces, including laser texturing, machining, ion beam texturing, and etching techniques. Those micropits (also known as oil pockets, holes, pits, dimples, and cavities) may reduce friction by providing lift themselves as a microhydrodynamic bearing and by acting as a reservoir for lubricant, thereby improving seizure resistance. Holes can also serve as a trap for wear debris in sliding.

Laser texturing on the cylinder surface can be used to minimize the risk of bore polishing, especially in the reversal zone of the cylinder [24]. Bore polishing occurs when the cylinder liner topography is removed [25]. This process leads to lubrication starvation in addition to welding and material transfer between the sliding surfaces and results in scuffing of the surfaces and eventual failure of the engine [26]. Golloch et al. [27] describes a tribological comparison between a conventional liner surface and a laser-structured liner in which they measure wear, oil film thickness, and friction force. Their results indicate that, in terms of tribological behavior, the laser-structured liner surface performed better than the conventional plateau-honed surface, leading to lower fuel consumption and $25 \%$ less wear.

The influence of rectangle dimples with a flat bottom on the friction of parallel surfaces has been investigated experimentally and in simulations [28]. The positive effect of dimples in lowering the friction for parallel surfaces was observed over the range of larger sliding speeds, larger loads, and smoother surfaces. The presence of such dimples on parallel surfaces can particularly reduce the friction coefficient for cases with a smaller ratio of film thickness to roughness $(h / R q)$, small roughness, or larger load. Moreover, these authors found that, under the same conditions, longitudinal surfaces behaved better than transverse ones in lowering friction. For the case of the larger ratio of film thickness to roughness $(h / R q)$, larger roughness, or smaller load, the change in the friction coefficient for the parallel surfaces due to the dimple effect depends on the combined influence of these factors.

The positive effect of oil pockets in reducing frictional losses occurs even for hard-wearing surfaces, particularly for cylinder liners coated by diamond-like carbon (DLC) or Nikasil. Rahnejat et al. [29] tested three different cylinder liner configurations: (1) standard cross-hatched at 25-35 to the horizontal plane, coated with Nikasil; (2) standard cross-hatched Nikasil with a laser-etched pattern; (3) a DLC liner. They observed that the laser-etched liner showed a continual performance improvement of up to
$4.5 \%$ over the standard liner, with the maximum benefit arising at the engine speed of the peak torque.

Costa et al. [30] investigated the influence of surface topography on lubricant film thickness for the reciprocating sliding of patterned plane steel surfaces against cylindrical counterbodies under hydrodynamic lubrication conditions. They used patterns of circular depressions, grooves, and chevrons, while the fractional area coverage, depth, width, and sliding orientation relative to the texture were systematically varied. They found that the chevron patterns were the most effective in increasing hydrodynamic film thickness, while grooves were the least effective.

A completely different approach, but one that clearly improves engine efficiency and piston-cylinder $(\mathrm{P}-\mathrm{C})$ device wear resistance, concerns texturing the surface of the piston rings by laser treatment. The aim of the experimental studies performed by Etsion and Sher [31] on the diesel engine was to evaluate the positive effect of the surface texture of piston rings on fuel consumption and exhaust gas composition. Laser texturing improves the seizure resistance of smooth surfaces, especially for small sliding velocity and high loads and at low oil viscosity [32]; as such, this methodology is the preferred approach for shaping the surfaces of piston ring and cylinder liners, especially in the ring reversing area.

The surface topography can be inspected using contact or non-contact (optical) instruments in two (2D) or three (3D) dimensions. 2D contact methods, usually timeconsuming and not so powerful as 3D optical ones, can introduce some errors due to morphological filtration effects [33]. Nevertheless, the sources of 2D measurement uncertainty are rather well known and can be eliminated. 2D contact methods also provide a high accessibility to the measuring surface and are flexible and normalized. 3D parameters are much more informative, but they often correlate internally and with some adequate $2 \mathrm{D}$ parameters [34]. Modern confocal microscopes and white-light interferometers ensure an abundance of 3D information on cylinder liner surface topography. The data obtained with these instruments are used in morphological algorithms, such as the watershed transform, to detect and separate the function-relevant structures, which can be described by a set of structural parameters. Statistical analysis of these parameters provides a functional characterization of the complete measured surface. The calculation of honing angles shows the possibilities provided by this flexible method of surface evaluation.

On occasion, multiple reflections coming from oil films or surface coatings can be a problem in optical research. They can also appear at step edges, when light above and beneath the edge is reflected. White light interferometry also has problems with speckles and "bat-wings" [33] when the surface structures have a size close to the 
coherence length of the white light interferometer. In addition, confocal microscopes sometimes show overshooting in their data sets near sharp edges [35].

\section{The Aims and Object of the Investigations}

The main aim of the investigations described in the paper was to study the effect of various conditions of initial surface roughness of the honing cylinder liner on gasoline engine performance after the test bed running-in operation and following the operation cycle providing intensified abrasive wear of the P-C device.

Five air-cooled aircraft engines FRANKLIN 4A-235B31 (technical characteristics are given in Table 1) were used in all tests. The surface of each tested cylinder liner, made of gray cast iron, was machined with different honing tools and machining settings according to the present stateof-the-art, three-stage honing procedure. In general, the cylinder liners after their thermal clamping in the cylinder body were bored and roughly honed with sticks of grit size D107 to form the bore base. They then passed through the two-stage honing process, including coarse and plateau honing. The first step produces a rough surface with coarse peaks and valleys as a result of the abrasive honing grits ploughing the liner material. The second step-plateau honing with abrasive grits of a smaller size-replaces the coarse honing peaks with a much finer texture but leaves the valleys unaltered. All operations were performed on a WMW SZS-250 machine tool with hydraulic clamping of the honing sticks, which were fastened in the head of the innovation design [36]. In the coarse-honing procedure, diamond sticks of grit size D54 or pure green carborundum sticks (SC, 99C) of grit size 100 and 120 alternatively mixed with microcrystal corundum (5SGG) of 150 grain size were used. Plateau honing was performed using D7 diamond sticks or green carborundum sticks (VC) of grit size 320 and 500. The operation settings were the input variables in the experiment and concerned honing time (10-75 s), stick pressure (0.6-1.5 $\mathrm{MPa}$ for diamond sticks, 0.2-0.5 $\mathrm{MPa}$ for carborundum sticks), honing tangential velocity (19-23 $\mathrm{m} / \mathrm{min}$ ), and average axial velocity of the honing head (10-12 m/min). Both machining motion velocities were synchronized to maintain a honing angle of $50^{\circ}$. The honing allowance was $0.07-0.11 \mathrm{~mm}$ for rough honing and total $0.02-0.05 \mathrm{~mm}$ for coarse and fine (plateau) honing. Using these settings, we varied the cylinder liner roughness parameters as shown in Table 2. The liner surface topography was checked with Form Talysurf Series 2 profilometer, with the $2-\mu \mathrm{m}$ spherical tester tip located $25 \mathrm{~mm}$ from the top end of the liners. Measurements were performed along four reciprocally perpendicular lengths of $17.5 \mathrm{~mm}$, with sampling steps of $0.25 \mu \mathrm{m}$ and a tip velocity of $0.5 \mathrm{~mm} / \mathrm{s}$. The Gaussian filter of $\lambda c=2.5 \mathrm{~mm}$ cut-off was applied.

Table 1 FRANKLIN 4A-235-B31 engine technical specification

Engine type: FRANKLIN 4A-235-B31

Engine type: FRANKLIN 4A-235-B31

Valves arrangement: OHV

Ignition system: spark ignited (twin spark plugs)

Fuel feeding system: carburettor

Cooling medium: air

Number of cylinders: 4

Cylinders arrangement: opposite

Shaft direction: horizontal

Cylinder bore: $117.45 \mathrm{~mm}$

Piston stroke: $88.9 \mathrm{~mm}$

Swept volume: $3,851 \mathrm{ccm}$

Compression ratio: 8.5

Rated power: $116 \mathrm{HP} / 85.3 \mathrm{~kW}$ at $2,800 \mathrm{rpm}$

Maximum torque: $295 \mathrm{~N} \mathrm{~m}$ at 2,600 rpm

Overall length: $738 \mathrm{~mm}$

Overall height: $583 \mathrm{~mm}$

Width: $792 \mathrm{~mm}$

Dry weight: $103 \mathrm{~kg}$

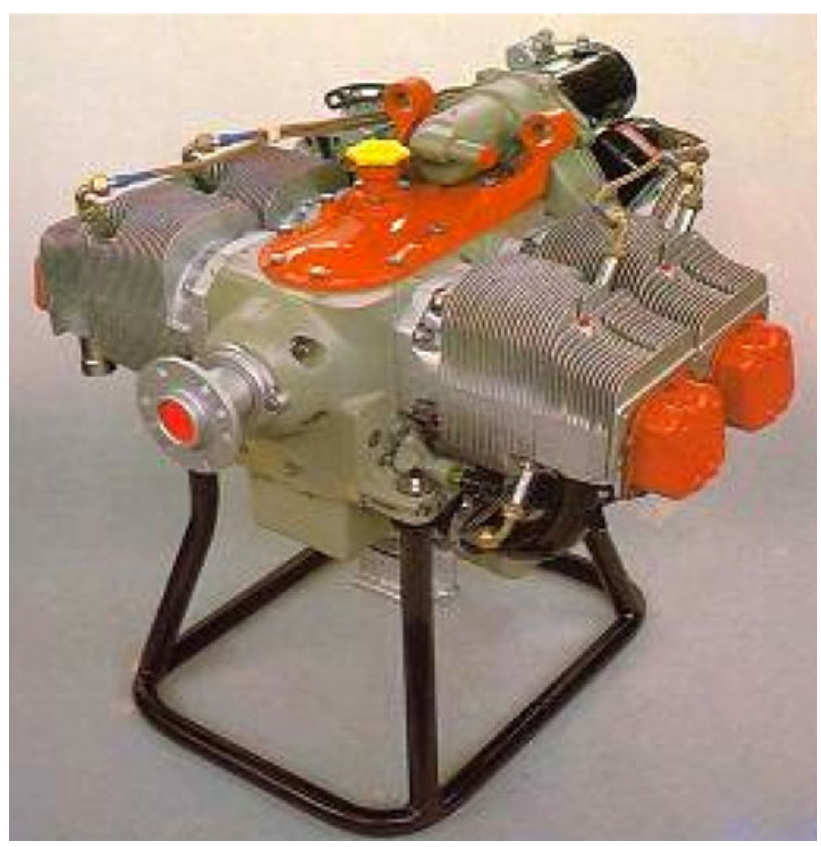


Table 2 Five FRANKLIN 4A-235-B31 aircraft engines with a different cylinder liner surface topography

\begin{tabular}{|c|c|c|c|c|c|}
\hline \multirow[t]{2}{*}{ Roughness profile parameters } & \multicolumn{5}{|l|}{ Engine no. } \\
\hline & 1 & 2 & 3 & 4 & 5 \\
\hline Root mean square of heights in a profile roughness $(R q, \mu \mathrm{m})$ & $0.83-1.01$ & $.84-1.02$ & $.38-.46$ & $.67-.81$ & $.88-1.02$ \\
\hline $\begin{array}{l}\text { Average maximum height for the five sample length: the roughness profile } \\
(\text { Rtm }, \mu \mathrm{m})\end{array}$ & $3.53-4.65$ & $3.31-4.43$ & $1.40-2.52$ & $2.56-3.68$ & $4.13-5.35$ \\
\hline Maximum height of the profile $(R t, \mu \mathrm{m})$ & $4.18-5.46$ & $4.76-6.04$ & $2.32-3.59$ & $3.08-4.36$ & $6.82-8.10$ \\
\hline $\begin{array}{l}\text { Average third highest peak to third lowest valley height within one five } \\
\text { sample length: the roughness profile }(R 3 z, \mu \mathrm{m})\end{array}$ & $2.57-2.99$ & $2.72-3.14$ & $1.03-1.45$ & $2.00-2.42$ & $1.81-2.23$ \\
\hline Maximum height of the profile $(R v, \mu \mathrm{m})$ & $2.67-3.51$ & $2.26-4.73$ & $1.33-1.88$ & $1.79-2.78$ & $2.03-4.59$ \\
\hline $\begin{array}{l}\text { Slope of a linear regression performed through the valley region } \\
(R v q, \mu \mathrm{m})\end{array}$ & $1.39-2.03$ & $1.61-2.00$ & $0.81-1.27$ & $1.05-1.58$ & $1.33-1.77$ \\
\hline Average absolute slope $\left(R \Delta q,^{\circ}\right)$ & $2.80-3.39$ & $2.23-2.73$ & $1.14-2.05$ & $2.39-2.65$ & $2.31-3.10$ \\
\hline Linear triangle area for valleys $(A 2, \mu \mathrm{m})$ & $14.6-27.6$ & $18.9-27.6$ & $6.6-9.6$ & $11.3-24.0$ & $18.2-26.6$ \\
\hline Maximum profile peak height $(R p, \mu \mathrm{m})$ & $1.15-2.32$ & $1.04-2.76$ & $0.75-1.94$ & $1.00-1.88$ & $0.92-1.33$ \\
\hline Reduced peak height $(R p k, \mu \mathrm{m})$ & $0.49-0.70$ & $0.49-0.87$ & $0.21-0.40$ & $0.33-0.73$ & $0.17-0.36$ \\
\hline Core roughness depth $(R k, \mu \mathrm{m})$ & $1.05-2.75$ & $1.05-2.14$ & $0.87-1.53$ & $1.23-2.50$ & $0.93-1.49$ \\
\hline Reduced valley depth $(R v k, \mu \mathrm{m})$ & $1.41-1.58$ & $1.53-1.77$ & $0.71-0.96$ & $1.41-1.60$ & $1.34-1.62$ \\
\hline $\begin{array}{l}\text { Slope of a linear regression performed through the plateau region } \\
(R p q, \mu \mathrm{m})\end{array}$ & $0.69-0.97$ & $0.53-0.91$ & $0.35-0.52$ & $0.43-0.77$ & $0.34-0.47$ \\
\hline Linear triangle area for peaks $(A 1, \mu \mathrm{m})$ & $2.3-2.8$ & $1.6-4.2$ & $0.7-1.5$ & $1.0-2.3$ & $0.5-1.0$ \\
\hline Peak mean height in a seven-peak profile roughness $(Z s, \mu \mathrm{m})$ & $0.03-0.04$ & $0.58-0.71$ & $0.01-0.02$ & $0.63-0.76$ & $0.02-0.03$ \\
\hline Peak height standard deviation in a seven-peak profile roughness $(\sigma, \mu \mathrm{m})$ & $0.11-0.14$ & $0.09-0.11$ & $0.06-0.07$ & $0.09-0.11$ & $0.09-0.11$ \\
\hline Mean peak radius in a seven-peak profile roughness $(\beta, \mu \mathrm{m})$ & $30.0-36.7$ & $28.0-34.3$ & $33.1-40.4$ & $31.2-38.2$ & $10.0-12.2$ \\
\hline Peak density $(\eta, 1 / \mu \mathrm{m})$ & $0.019-0.023$ & $0.019-0.024$ & $0.016-0.019$ & $0.019-0.023$ & $0.014-0.017$ \\
\hline Total waviness height $\mathrm{Wt}(\lambda \mathrm{c}=0.8 \mathrm{~mm}, \lambda f=8 \mathrm{~mm})(\mu \mathrm{m})$ & $0.85-1.27$ & $1.93-2.35$ & $.90-1.32$ & $1.11-1.53$ & $3.82-4.24$ \\
\hline
\end{tabular}

\section{Experimental Procedure}

\subsection{Testing Rig and Equipment}

Each of five tested FRANKLIN 4A-235-B31 engines was fitted with the brand-new cylinder sets consisting of a specific honed liner and standard piston, rings, pins, and valves. The engines drove an eddy-current dynamometer. The test house allowed testing with simulations of increased dustiness of the ambient by the system that doses road dust into the inlet manifold [9]. The engines were connected to the fuel and air-cooling installation. Additionally, an extra lubrication oil tank with cooling device was applied to avoid the effect of changing oil properties on research results. The oil was super-fine filtered. The engines were fuelled with Avgas 100LL (low-lead) aviation fuel that satisfied the requirements of ASTM D910-04a and Defence Standard 91-90 (DERD 2485); semi-synthetic anti-wear AeroShell Multigrade 15 W-50 oil was used as the lubricant.

The main working and performance parameters of the engine were continuously monitored; for instance, the temperature of the cylinders was monitored with thermocouples mounted below the spark-plug packing washers.
Figures 1 and 2 show the research stand, which consisted of three systems: system supplying abrasive medium, hydraulic system for oil cleaning and conditioning, and the engine itself. The oil cleaning/conditioning system was applied in order to limit the wear of the other elements (apart from the piston-piston ring-cylinder assembly) that could appear due to grinding flour settling into the lubrication oil. The principle of this system is based on the growth of capacity of circulated oil as well as improved rigor of the filtration - the system includes an additional filter. The whole system is presented in detail in Fig. 2. It consists of an oil reservoir (3), hydraulic pump (4), pressure-reducing valve (5), flow controller (6), additional $5-\mu \mathrm{m}$ grade filter (7), and cut-off valves $(10,11,12)$. It was switched on only in the cases where it was found that the other parts of the engine could be severely worn. Figure 2 also shows how the grinding particles feeder was connected to the engine inlet manifold. While Fig. 2 shows the scheme for an automotive engine, the same systems with few modifications were used for the aircraft engines tested here. The feeder was located over the engine carburetor (18), in a convergent-divergent nozzle (Laval nozzle). The particles were carried from the feeder into the carburetor by a flexible conduct pipe through convergent nozzle (17). 
Fig. 1 View of the research stand for accelerated running-in and intensified wear investigations: 1 Cooling system, 2 muffler, 3 system supplying abrasive medium, 4 dynamometer

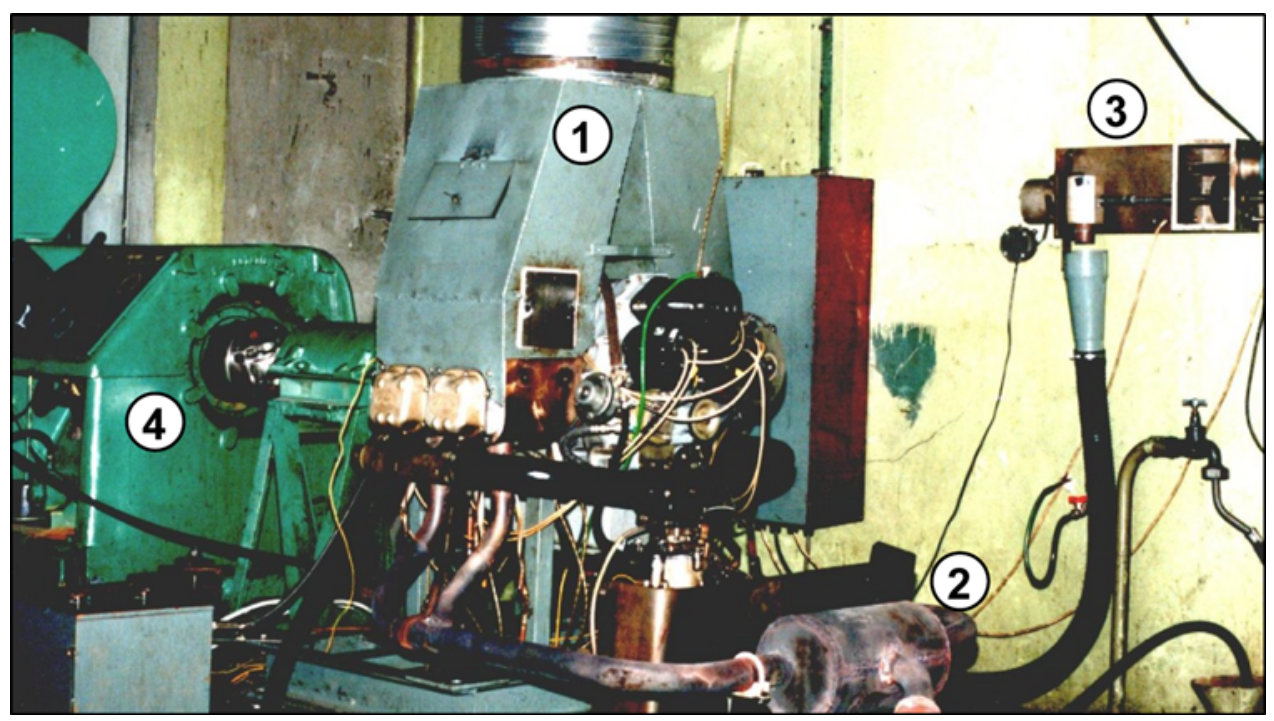

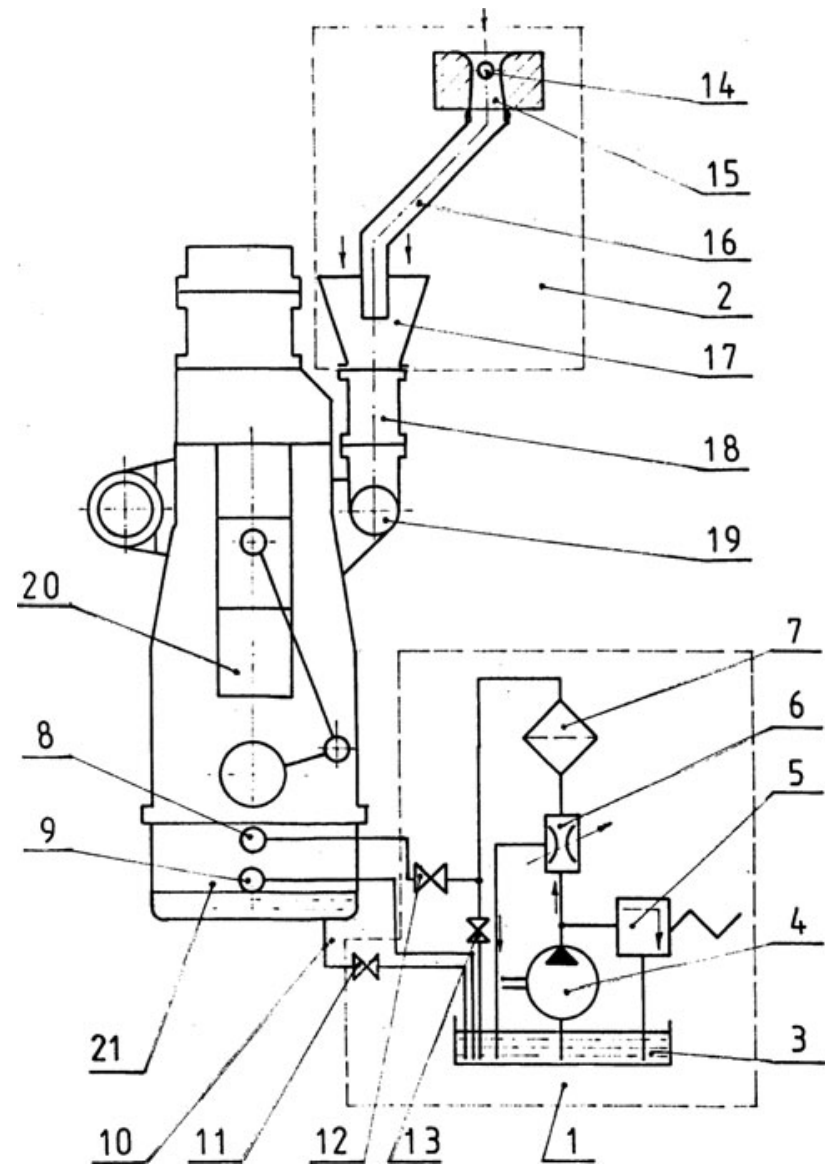

Fig. 2 Layout of the research stand for accelerated running-in and intensified wear investigations: 1 hydraulic system for additional oil cleaning, 2 system supplying abrasive medium, 3 oil reservoir, 4 hydraulic pump, 5 pressure reducing flow, 6 flow controller, 7 oil filter, 8,9 connections, 10 drain, $11,12,13$ cut-off valve, 14 dust feeder, 15 convergent-divergent nozzle (Laval nozzle), 16 supply conduct, 17 convergent nozzle, 18 engine carburettor, 19 inlet manifold, 20 engine cylinder, 21 oil sump
This system allows for a uniform and uninterrupted supply of grinding particles into an engine carburetor at a constant concentration (circa $8 \mathrm{mg} / \mathrm{m}^{3}$ ) for a wide range of engine operations and inlet air flows. At full load operation, road dust was added at a maximum amount of $1.3 \mathrm{~g} / \mathrm{h}$.

\subsection{Testing Procedure}

In the first stage, the engines were run in the fired runningin regime for $10 \mathrm{~h}$ at 1,400-2,800 rpm and altered load (Fig. 3a). The full-open throttle speed characteristic and total efficiency of the engines were then checked. The rough engine performance results were reduced to normal conditions, i.e., an atmospheric pressure of 760 Torr and an ambient temperature of $15^{\circ} \mathrm{C}$. All tested engines were disassembled in order to be able to measure $\mathrm{P}-\mathrm{C}$ device wear for detailed analysis of wear processes [37]. Similarly to the after-machining analysis, the same 2D contact instrumentation and procedures were used. At this stage, given the heavy weight of the cylinders $(12 \mathrm{~kg})$ and the necessity to carry out non-destructive tests on the blind cylinders at a depth of $160 \mathrm{~mm}$ (each cylinder makes one piece with the head), it was still impossible to perform 3D measurements using Optical Profiling Systems (e.g., Wyko NT9100; Veeco, Plainview, NY) or contact instruments (Talyscan 150; Taylor Hobson Precision, Leicester, UK).

The engines were re-assembled and run under artificial conditions that simulated increased dustiness of the ambient air. An elementary 3-h lasting effort cycle that combines $2 \mathrm{~h}$ and $50 \mathrm{~min}$ of the full load working at 2,800 rpm and $10 \mathrm{~min}$ of the idle load (Fig. 3b) was repeated seven times for a total operating time of $21 \mathrm{~h}$. This self-elaborated testing schedule, which included the intensified wear periods under the dusting conditions, ensured statistically 

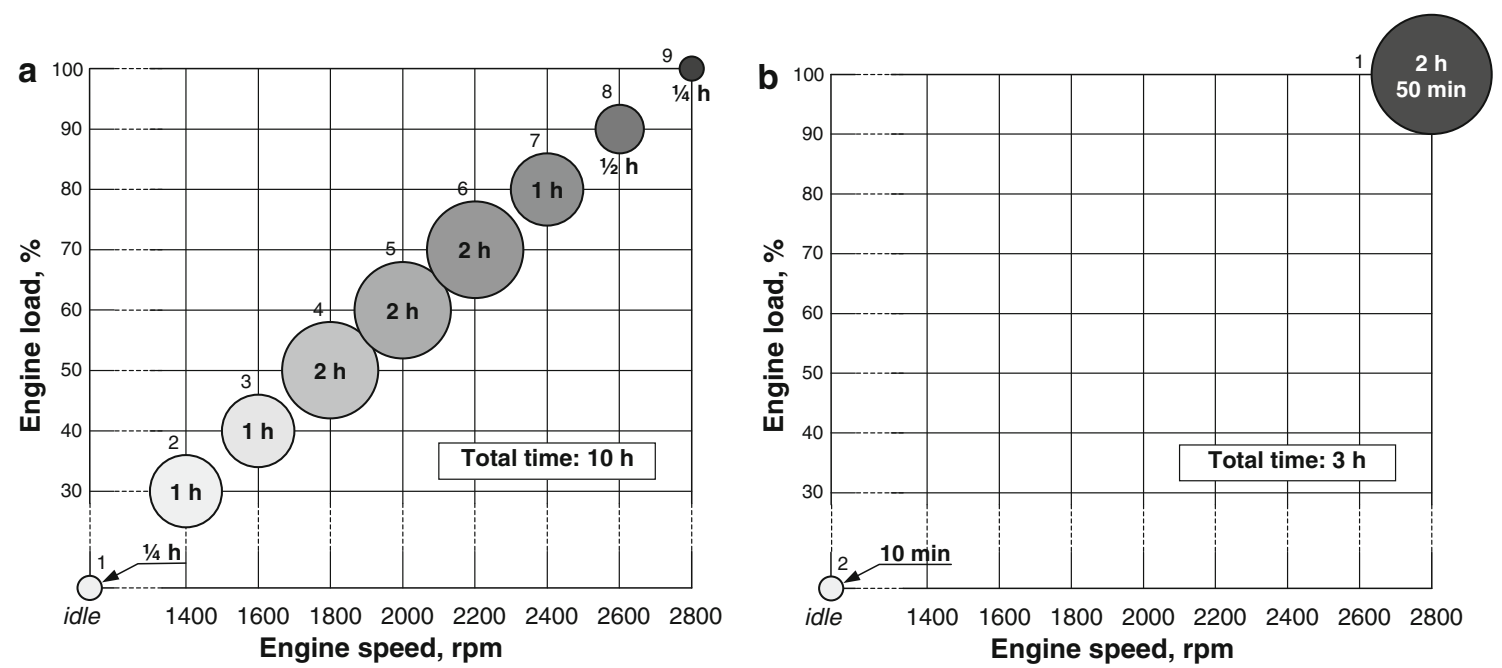

Fig. 3 Engine speed and load schedule for the running-in operation (a) and the intensified wear elementary test (b)

the same wear ratio of the $\mathrm{P}-\mathrm{C}$ device as the 1500-h-long durability test of the engine in real flying conditions.

The engine brake tests and established wear measuring procedures were performed again at the end of the whole research cycle. In addition, the 3D liner surface topography was evaluated using the Talyscan 150 contact scanner for both the originally honed and worn cut-out liner segments on samples of the tested area measuring $4 \times 4 \mathrm{~mm}$. The scanner tip shape was spherical with a diameter of $2 \mu \mathrm{m}$; tip velocity was set at $0.5 \mathrm{~mm} / \mathrm{s}$, while the sampling step and sampling path distance were $5 \mu \mathrm{m}$.

\section{Results and Discussion}

A preliminary analysis of the output parameters collected for all five engines after each stage of the experiment shows noticeable inter-engine distinctions. The rates of net output power $\mathrm{Ne}$, torque $\mathrm{Mo}$, brake-specific fuel consumption (BSFC) $g e$, total efficiency $\eta o$, and the concentration of hydrocarbons and carbon oxides $[H C(\mathrm{ppm})$ and $\mathrm{CO}(\%)$, respectively] in exhaust are shown in Figs. 4 and 5 after $10 \mathrm{~h}$ of running-in operation and execution of 21-h-long intensified abrasive wear cycle, respectively. Variations in the characteristic values of these parameters for each stage were as follows:

- $\mathrm{Ne}=(80.6-84.7)$ and (78.5-83.0) kW at 2,800 rpm;

- $M o=(276.6-294.2)$ and (272.5-282.2) N m at 2,600 rpm;

- $g e=(335.5-391.7)$ and $(347.2-406.8) \mathrm{g} /(\mathrm{kW} \mathrm{h})$ at $2,800 \mathrm{rpm} ;$

- $\quad \eta o=(20.9-24.4)$ and $(20.1-24.1 \%)$ at $2,800 \mathrm{rpm}$;

- $C O=(2.8-7.1)$ and $(4.7-8.1 \%)$ at $2,800 \mathrm{rpm}$;
- $\quad H C=(78-135)$ and $(95-212) \mathrm{ppm}$ at 2,800 rpm.

The results indicate that the topography of the cylinders of engine no. 2 was the most effective with respect to all analyzed parameters, including performance and environmental factors, with the exception of BSFC and total efficiency, which worsened at the end of the test (Figs. 4, 5). Engines no. 3 and 4 were similar to one another in terms of performance which, in fact, was rather weak except for the environmental parameters. Engine no. 1 showed the most balanced and relatively good parameters for both stages of its operation, and engine no. 5, although showing good performances, was saddled with the highest exhaust emission.

The effort running of the engines caused internal wear and performance deterioration. The changes made to the topography of the cylinder liners throughout the experiments demonstrated the abrasive mechanism of their wear (Fig. 6). No bore polishing areas were observed. Michalski and Woś [37] present a more detailed report on the characteristics of wear shown by the whole $\mathrm{P}-\mathrm{C}$ device. Although the measured wear turned out to be rather high, the engine parameters dropped moderately. Statistically, the average power of the five engines after the running-in operation and after carrying out the full test decreased slightly by $2.5 \%$ from $83.0 \pm 1.7$ to $80.9 \pm 1.8 \mathrm{~kW}$ (Table 3). The same trend was observed for torque mean value, which changed from $285.5 \pm 7.3$ to $277.9 \pm 4.1 \mathrm{~N} \mathrm{~m}$, which is also a reduction of $2.5 \%$. The fuel consumption increased by $3.6 \%$ from $364.3 \pm 21.6$ to $377.4 \pm 22.7 \mathrm{~g} /(\mathrm{kW} \mathrm{h})$, while the total efficiency of the engines dropped by $2.2 \%$ from $22.6 \pm 1.3$ to $22.1 \pm 1.7 \%$. A larger change was noticed for exhaust emission factors: $\mathrm{CO}$ increased by $35 \%$ and $\mathrm{HC}$ by $40.8 \%$ based on a comparison of stage-to-stage amounts. 
Fig. 4 Performance characteristics of the engines after $10 \mathrm{~h}$ of running-in operation
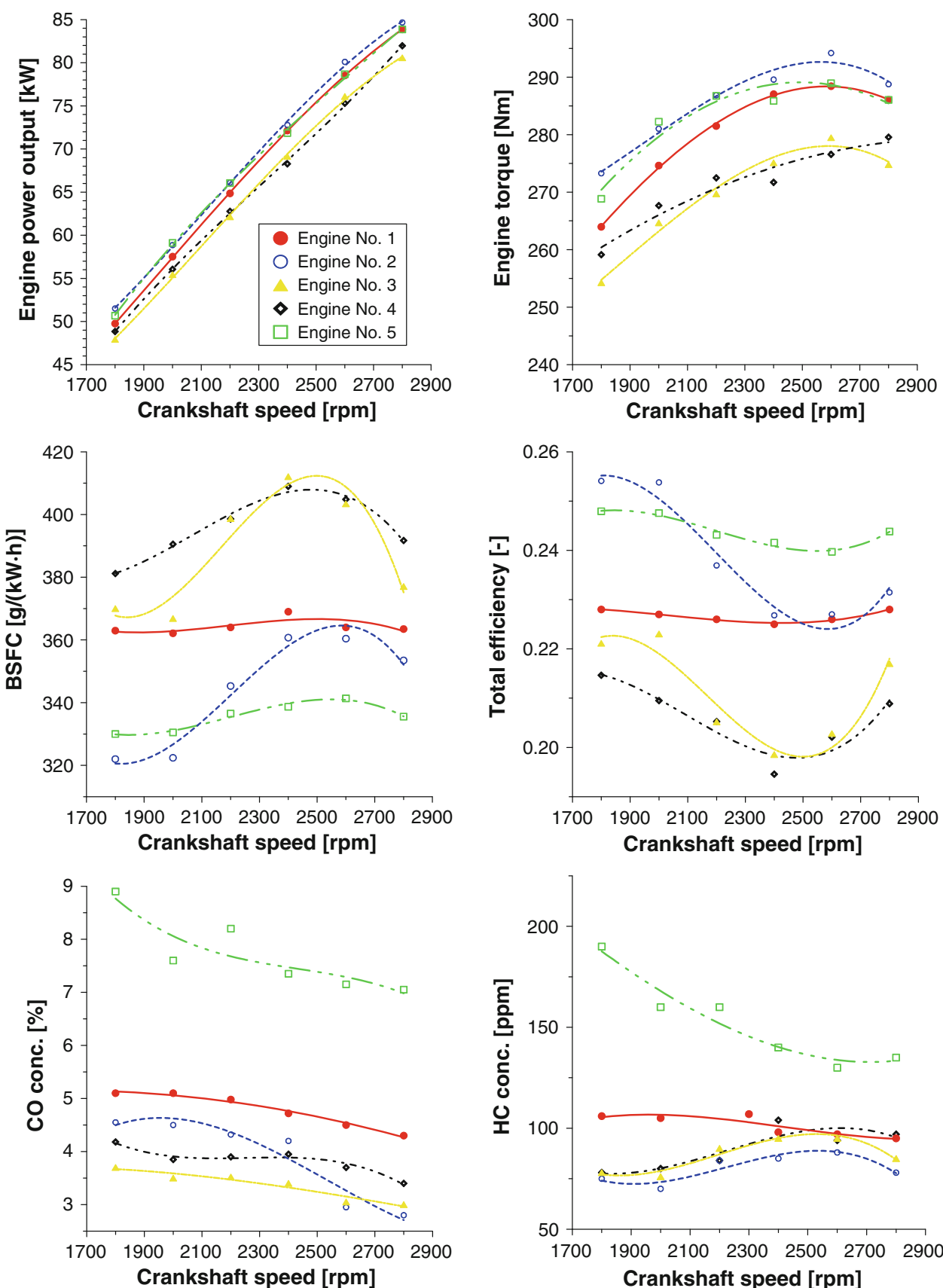

Further extensive analysis was carried out to determine more precisely the relationships between the microstructure of the original cylinder liner and the output parameters of the engines. For this to be known, a number of parameter-to-parameter linear correlations have been evaluated; the adequate correlation factors are presented in Table 3, with the values in bold indicating very high correlations $(R x y \geq 0.90)$. In general, the roughness parameters $R q$, $R v k, R v q, R \Delta q, A 2$, and $\beta$, are closely linked with power $N e$ and torque $M o$ of the tested engines. However, only two of these, $R v q$, and particularly $A 2$, reveal a much stronger correlation with all of the engine parameters analyzed, including total efficiency, fuel consumption, and harmful compound emissions.

The pre-testing and mid-testing measurements allowed multiplying and scattering inputs to be obtained for use in an overall statistical analysis of the problem. In this study, the after-machining cylinder liner surface topography was treated as an initial state for post-running-in engine performances, and the mid-stage surface topography become the initial microstructure stipulating the engine outputs after their effort testing. The relationships between all of the engine parameters analyzed and the most susceptible condition (linear triangle area for valleys $A 2$ ) are illustrated in Fig. 7, including 
Fig. 5 Performance

characteristics of the engines after the full testing cycle operation
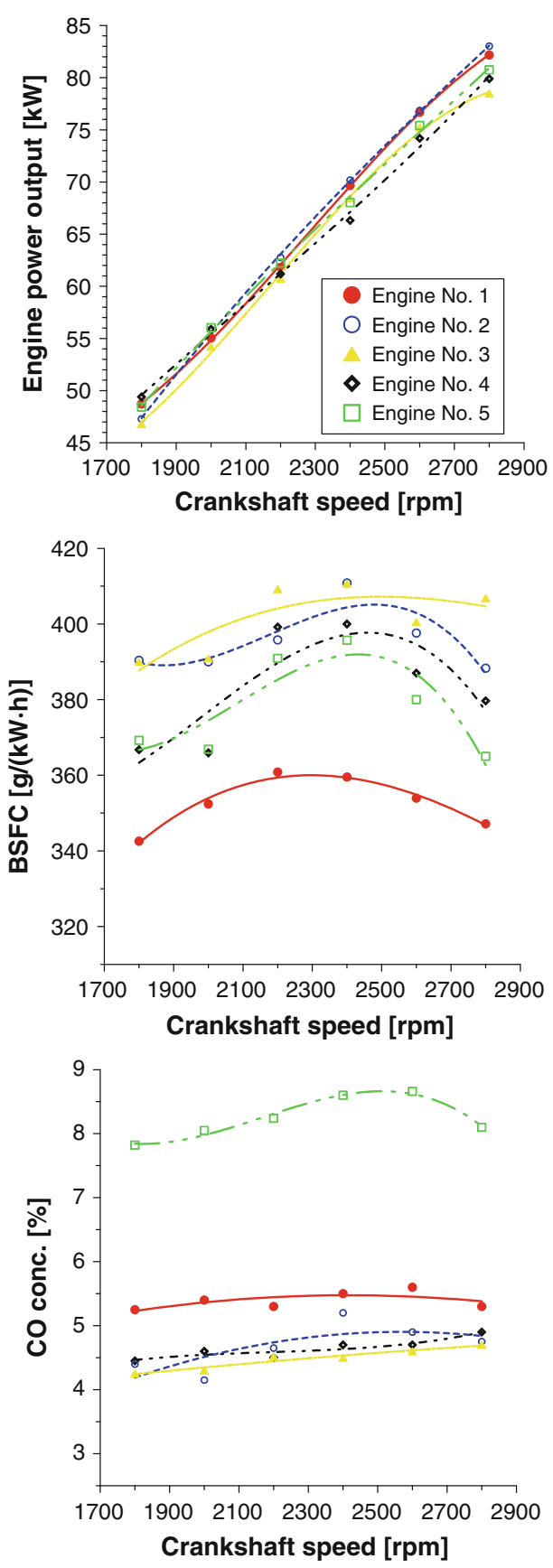
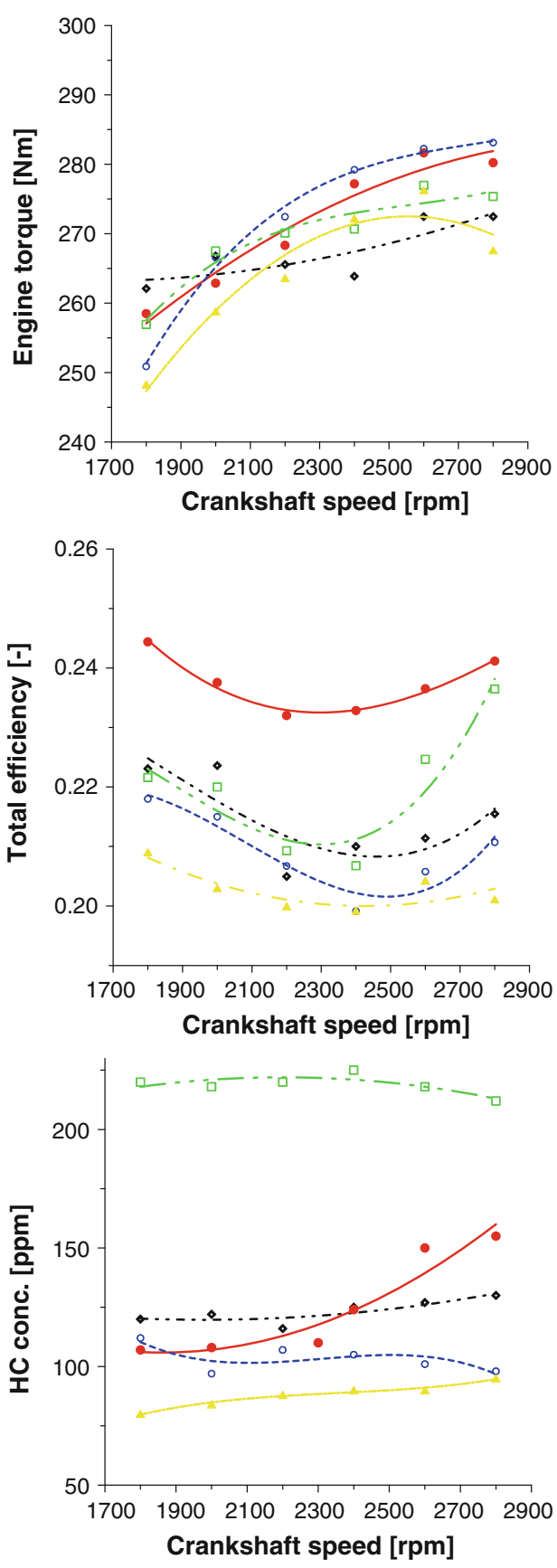
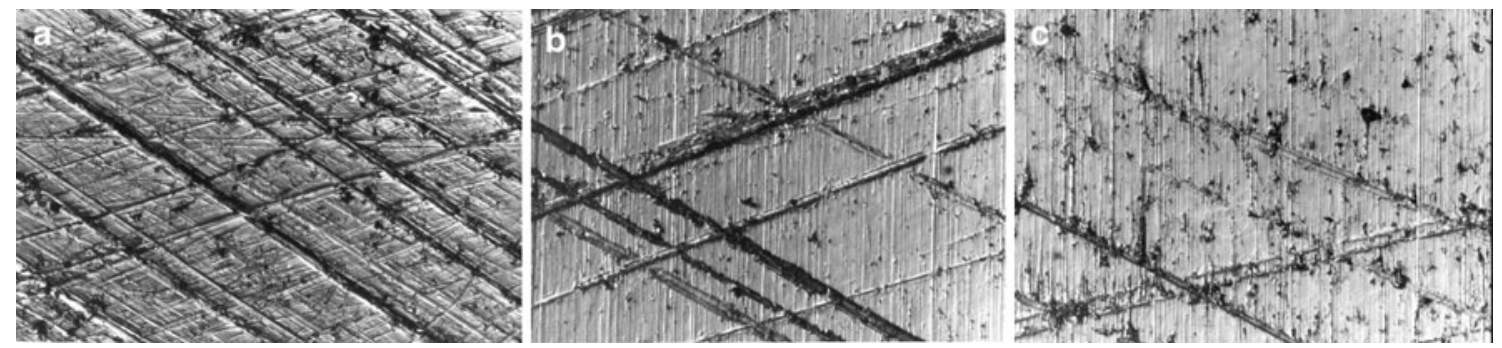

Fig. 6 Image of "fax-film" negative replication of cylinder liner surface after: a honing, b 10-h running-in operation, c 21-h intensified wear operation. Observations under a Neophot 2 microscope, magnification $40 \times$ 


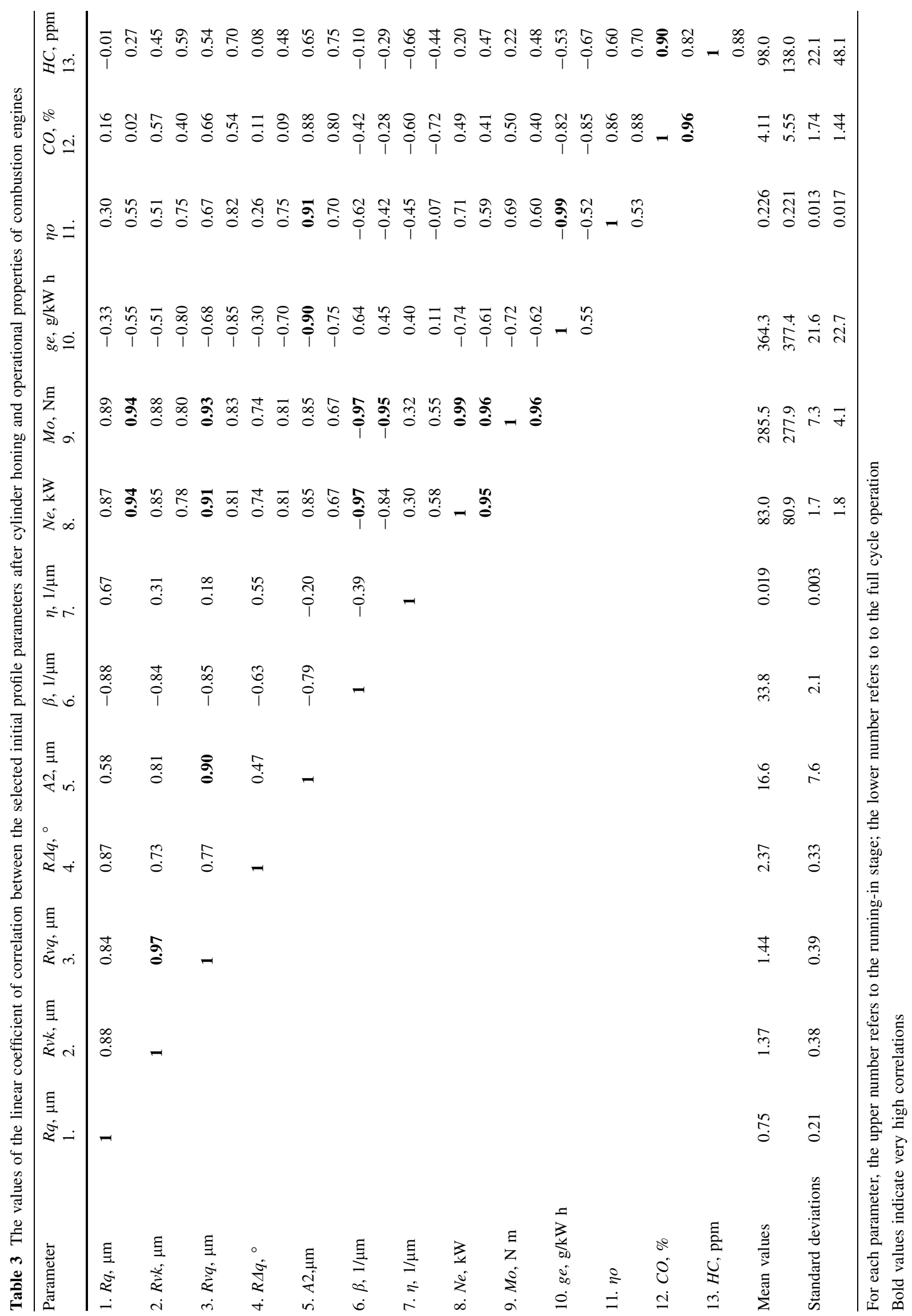


Fig. 7 Characteristics of engine output parameters versus pretesting value of cylinder liner roughness parameter $A 2$ (linear triangle area for valleys).

Confidence intervals $=0.95$
Fig. 8 Correlation of equivalent two- and threedimensional parameters: a linear $A 2$ and areal $\mathrm{Sa} 2$ triangle area for valleys, $\mathbf{b}$ root mean square deviation of the profile $R q$ and the surface $S q$ evaluated on the basis of 80 pairs of cylinder liner measurements. Confidence intervals $=0.95$
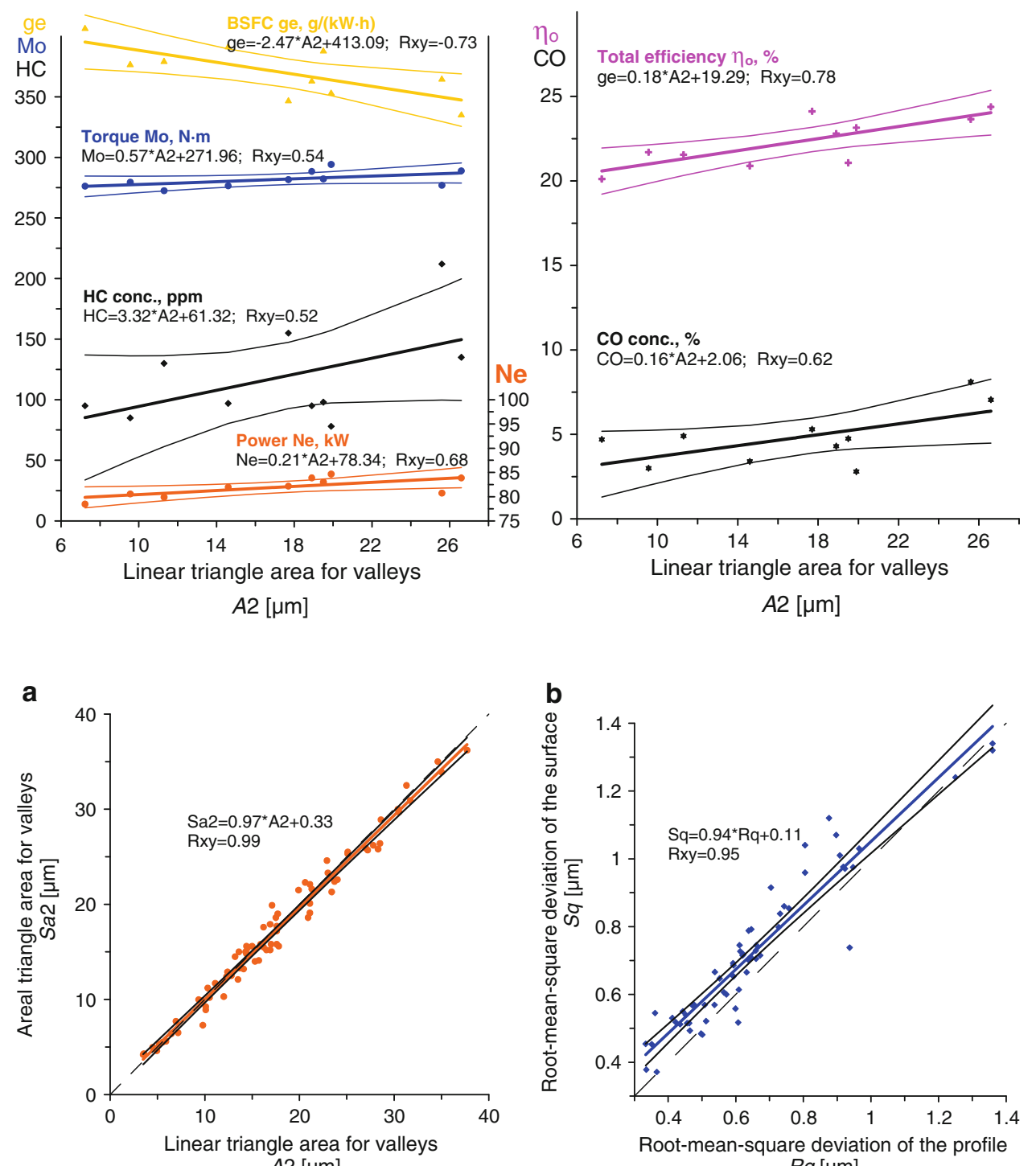
$A 2[\mu \mathrm{m}]$

$R q[\mu \mathrm{m}]$ linear regression modeling results. For $A 2$ ranging from 7.2 to $26.6 \mu \mathrm{m}$, all engine parameters showed a correlation with coefficients exceeding 0.5 . The slopes of the regression lines proved that the engine performed better when the value of the A2 parameter was higher; inversely, the environmental factors ( $\mathrm{CO}$ and $\mathrm{HC}$ emission) became significantly worse with increasing $A 2$. Because the $A 2$ parameter determines the volume of oil reserve on the liner surface, these phenomena seem to be directly connected with better lubrication; thus, with high values of the $A 2$ parameter, there were both lower friction losses and an increased oil consumption problem during engine testing.

\section{Conclusions}

The results of this study demonstrate distinct variations in engine performance due to differences in the initial microstructure of the initial cylinder liner surface. The slope of a linear regression of valley region $R v q$ and, particularly, the linear triangle area for valleys $A 2$ are the roughness parameters that should be taken into consideration at cylinder liner surface shaping. Higher values of $R v q$ and $A 2$ were associated with improvements in the main engine parameters: output power $\mathrm{Ne}$, torque $\mathrm{Mo}$, fuel consumption $g e$, and total efficiency $\eta o$. There was a very strong-but negative-relation appears between the cylinder liner roughness parameters tested and harmful exhaust emission, including carbon oxide $C O$ and hydrocarbons $H C$. These results confirm that with an increased higher cylinder liner surface, the oil retention volume corresponds to the $R v q$ and $A 2$ parameters and that there is a higher oil consumption and, consequently, a greater emission of $\mathrm{CO}, \mathrm{HC}$, and soot [8, 12]. This is a limitation for acceptable values of $R v q$ and $A 2$ parameters, which must be balanced within an overall cylinder liner manufacturing technology. 
A number of the findings reported here concerning the $R q$ and $A 2$ parameters may be extrapolated to the equivalent areal parameters: the root mean square roughness of the surface $S q$ and areal triangle area for valleys $S a 2$. Additional 3D measurements of the liner surfaces performed at the end of the bench experiments combined with results acquired from other cylinder liner samples, but machined with the same technology, showed a close, nearly 1:1 linear dependence between them (Fig. 8). Similar convergences can be also found in [34].

Acknowledgments The authors wish to thank the Polish Ministry of Science and Higher Education for his financial support to this work through the research grant No 7 T07D 009 95C/2731.

Open Access This article is distributed under the terms of the Creative Commons Attribution Noncommercial License which permits any noncommercial use, distribution, and reproduction in any medium, provided the original author(s) and source are credited.

\section{References}

1. Suchecki, A., Sordyl, A., Bielaczyc, P., Jakóbiec, J.: Analysis of the oil consumption in the modern Euro 4 turbocharged compression-ignition engine. Proc. PTNSS Congr. 2005, P05-C030 (2005)

2. Taylor, C.M.: Automobile engine tribology-design considerations for efficiency and durability. Wear 221, 1-8 (1998)

3. Wiemann, L.: Die Bildung von Brandspuren auf den Lauflachen der Paarung Kolbenring-Zylinder in Verbrennungsmotoren. Motortech Zeits 32, 43-49 (1971)

4. Santochi, M., Vignale, M., Giusti, F.: A study on the functional properties of a honed surface. CIRP Ann. 31, 431-434 (1982)

5. Jeng, Y.: Impact of plateaued surfaces on tribological performance. Tribol. Trans. 39, 354-361 (1996)

6. Von Robota, A., Zwein, F.: Einfluss der Zylinderlaufflächentopografie auf den Ölverbrauch und die Partikel-Emissionen eines DI-Dieselmotors. MTZ 60, 246-255 (1999)

7. Pawlus, P.: A study of the dependence of the functional properties of the cylinder liner surface layer on the operating conditions. Proc. IMechE J.: J. Eng. Tribol. 210, 17-27 (1996)

8. Johansson, S., Nilsson, P.H., Ohlsson, R., Anderberg, C., Rosén, B.G.: New cylinder liner surfaces for low oil consumption. Tribol. Int. 41, 854-859 (2008)

9. Cisek, Z., Kunysz, J., Lejda, K., Michalski, J., Pawlus, P., Śmieszek, M., Ustrzycki, A., Zając, P.: Development of manufacturing technology for cylinder bore ensuring optimum engine performance (in Polish). Report from grant works No 7 T07D 009 95C/2731, contractor WSK "PZL-Rzeszów” Inc. Rzeszów University of Technology, Rzeszów (1996-1998)

10. Wang, S., Hu, Y.Z., Wang, W.Z., Wang, H.: Effects of surface roughness on sliding friction in lubricated-point contacts: Experimental and numerical studies. Trans. ASME J. Tribol. 129, 809-817 (2007)

11. Nilsson, B., Rosen, B.G., Thomas, T.R., Wiklund, D., Xiao, L.: Oil pockets and surface topography: mechanism of friction reduction. In: 11th Int Colloquium Surfaces, Addendum. Chemnitz, Germany (2004)

12. Hill, S.P., Kantola, T.C., Browa, J.R., Hamelink, J.C.: An experimental study of the effect of cylinder bore finish on engine oil consumption. SAE Paper No. 950938 (1995)
13. Organisciak, M., Cavallaro, G., Lubrecht, A.A.: Variable lubricant supply of a starved hydrodynamic linear contact: lubricant lateral flow for smooth and laser textured surfaces. Proc. IMechE J.: J. Eng. Tribol. 221(3), 247-258 (2007)

14. Jocsak, J., Li, Y., Tian, T., Wong, V.W.: Modelling and optimizing honing texture for reduction friction in internal combustion engines. SAE Paper 2006-01-0647 (2006)

15. Lejda, K., Woś, P.: A Preliminary Project Of Multi Cylinder, Variable Compression Ratio (VCR) Engine for Research Purposes. Combustion Engines, PTNSS-2009-SC-062, pp. 152-157 (2009)

16. Haasis, G., Weigmann, U.P.: New honing technique reduces oil consumption. Ind. Diam. Rev. 3, 205-211 (1999)

17. Pawlus, P., Cieślak, T., Mathia, T.: The study of cylinder liner plateau honing process. J. Mater. Process. Technol. 209, 6078-6086 (2009)

18. Klink, U., Flores, G.: Neue Feinbarbelotungsverfahren durch optimierte Prozesse. Firmeninterner Sonderdruck, Maschinenfabrik Gehring GmbH\&Co, Augsburg (2002)

19. Schmid, J.: Metallic composite materials for cylinder surfaces of combustion engines and their finishing by honing. In: Kainer, K.U. (ed.) Metal matrix composites. Custom-made materials for automotive and aerospace engineering, pp. 215-242. Wiley, Weinheim (2006)

20. Schmid, J.: Honing technology for optimal cast-iron cylinder liners. Eng. Technol. Int. 1/2, 108-109 (1999)

21. Schmid, J.: Optimized honing process for cast iron running surfaces. In: VDI Symposium: Piston Running Surfaces, Pistons and Conrods. Boblingen, Germany (2006)

22. Tomanik, E.: Friction and wear bench test for different engine liner surface finishes. Tribol. Int. 41, 1032-1038 (2008)

23. Pettersson, U., Jacobson, S.: Influence of surface texture on boundary lubricated sliding contacts. Tribol. Int. 36, 857-864 (2003)

24. Duffet, G., Sallamand, P., Vannes, A.B.: Improvement in friction by cw Nd: YAG laser surface treatment on cast iron cylinder bore. Appl. Surf. Sci. 205, 289-296 (2003)

25. Al-Khalidi, G.F., Eyre, T.S.: Bore polishing-identification and simulation. Tribol. Int. 20, 18-24 (1987)

26. Dong, W.P., Davis, E.J., Butler, D.L., Stout, K.J.: Topographic features of cylinder liners - an application of three-dimensional characterisation technique. Tribol. Int. 28, 453-463 (1995)

27. Golloch, R., Merker, G.P., Kessen, U., Brinkmann, S.: Benefits of laser-structured cylinder liners for internal combustion engines. In: 14th IntTribology Colloquium Proc, vol. 1. Technische Akademie, Esslingen, pp. 321-328 (2004)

28. Meng, F., Zhou, R., Davis, T., Cao, J., Wang, Q.J., Hua, D., Liu, J.: Study on effect of dimples on friction of parallel surfaces under different sliding conditions. Appl. Surf. Sci. 256, 28632875 (2010)

29. Rahnejat, H., Balakrishnan, S., King, P.D., Howell-Smith, S.: In-cylinder friction reduction using a surface finish optimization technique. Proc. IMechE D: J. Automob. Eng. 220, 1309-1318 (2006)

30. Costa, H.L., Hutchings, I.M.: Hydrodynamic lubrication of textured steel surfaces under reciprocating sliding conditions. Tribol. Int. 40, 1227-1238 (2007)

31. Etsion, I., Sher, E.: Improving fuel efficiency with laser surface textured piston rings. Tribol. Int. 42, 542-547 (2009)

32. Kligerman, Y., Etsion, I., Shinkarenko, A.: Improving tribological performance of piston rings by partial surface texturing. Trans. ASME J. Tribol. 127, 632-638 (2005)

33. Weidner, A., Seewig, J., Reithmeier, E.: 3D roughness evaluation of cylinder liner surfaces based on structure-oriented parameters. Meas. Sci. Technol. 17, 477-482 (2006)

34. Rosen, B.G., Anderberg, C., Ohlsson, R.: Parameter correlation study of cylinder liner roughness for production and quality control. Proc. IMechE B: J. Eng. Manuf. 222, 1475-1487 (2006) 
35. Langholz, N., Seewig, J., Reithmeier, E.: Robust surface fittingusing weights based on 'a priori knowledge about the measurement process. Wear 266, 515-517 (2009)

36. Michalski, J., Stelmach, L.: The honestone head for bore honing. Patents no. PL 181632 and PL 181665; Int Cl B24B 33/08 (1997)
37. Michalski, J., Woś, P.: The effect of cylinder liner surface topography on abrasive wear of piston-cylinder assembly in combustion engine. Wear (2010). doi:10.1016/j.wear.2010. 05.006 